\title{
Mapping the vegetation of the Lake Tana basin, Ethiopia, using Google Earth images
}

\author{
Chuangye Song ${ }^{1}$, Lisanework Nigatu ${ }^{2}$, Yibrah Beneye ${ }^{3}$, Abdurezak Abdulahi ${ }^{2}$, Lin Zhang $^{1}$, and \\ Dongxiu $\mathrm{Wu}^{1}$ \\ ${ }^{1}$ State Key Laboratory of Vegetation and Environmental Change, Institute of Botany, \\ Chinese Academy of Sciences, Beijing, China \\ ${ }^{2}$ School of Natural Resource and Environmental Sciences, Haramaya University, Dire Dawa, Ethiopia \\ ${ }^{3}$ College of Plant and Horticultural Sciences, Hawassa University, Awasa, Ethiopia \\ Correspondence: Chuangye Song (songcy@ibcas.ac.cn) and Wu Dongxiu (wudx@ibcas.ac.cn) \\ Received: 7 February 2018 - Discussion started: 9 April 2018 \\ Revised: 13 September 2018 - Accepted: 30 October 2018 - Published: 15 November 2018
}

\begin{abstract}
The basin of Lake Tana is one of the most important watersheds in the Nile Basin. It is of great significance to the economy and politics of Ethiopia. In the past, the natural vegetation of the Lake Tana basin was heavily damaged to facilitate the continued expansion of cropland. Vegetation must be conserved and restored to protect the natural environment and maintain the biodiversity of the Lake Tana basin. In this research, we mapped the vegetation of the Lake Tana basin through visual interpretation using high-spatial-resolution images provided by Google Earth and field survey data to provide detailed information of the actual vegetation state for planning conservation and restoration. A total of 33171 polygons were generated to represent the vegetation patches of the Lake Tana basin on the map, and the validation using surveyed vegetation plots indicated that $90 \%$ of the patches were correctly identified. The DOI of the dataset used for map production is https://doi.org/10.4121/uuid:48d45053-36f6-411b-96b1-7ae0e22d56d0. We expect that this vegetation map could benefit vegetation conservation and restoration in the Lake Tana basin.
\end{abstract}

\section{Introduction}

Lake Tana, located in the highlands of northwestern Ethiopia, is the country's largest freshwater lake and the third largest lake in the Nile Basin. Lake Tana is the source of the Blue Nile, and its basin is one of the most important catchments in the Nile Basin. It has rich natural resources and great potential for the development of irrigation, hydroelectric power, high-value crops, aquatic products, livestock products, and ecological tourism (Bijan and Shimelis, 2011). The Lake Tana basin is of critical significance to the economy and politics of Ethiopia. It also greatly influences the livelihoods of tens of millions of people in the lower Nile Basin.

Historically, there was a large area of Afromontane forest and many indigenous plant species in the Lake Tana basin; 172 woody species were observed in the basin, many of which were indigenous species (IFAD, 2007a). There are also large areas of wetlands and seasonally flooded plains, which provide multiple services to the local community and serve as a home for many endemic bird species (Ayalew, 2010; Bijan and Shimelis, 2011).

The population density and growth rate of the Lake Tana basin are very high. Over 2 million people reside in this basin, and the population density exceeds 150 people per square kilometer (Yimenu, 2005). The large population and high rate of population growth increase the demand for food. To meet this demand, large areas of forest, grassland, and wetland were transformed into cropland, and more livestock was raised on grassland. Deforestation and overgrazing have resulted in the destruction of great amounts of natural vegetation, a decline in biodiversity and forest stand density, desertification, and soil erosion (Alelign et al., 2007). To protect the natural environment and maintain biodiversity, it is vital that vegetation is restored and conserved in the Lake Tana basin (Bishaw, 2001). Since the 1990s, efforts have been un- 
dertaken to conserve and restore the natural vegetation of the Lake Tana basin (Bishaw, 2001; Teketay, 2001). However, its degradation and decline is still a major problem (IFAD, 2007b).

Detailed regional vegetation distribution data are the basis of vegetation management and conservation. Rational and scientific planning of vegetation conservation and restoration can only be conducted for the whole basin when the vegetation of the whole basin is well surveyed and mapped. However, vegetation maps that include the Lake Tana basin were made for Africa, East Africa, and Ethiopia at small scales, such as the vegetation map of Eritrea, Ethiopia, and Somalia at a scale of 1:5000000 (Pichi Sermolli, 1957), that of Ethiopia and Eritrea (von Breitenbach, 1963), that of Africa at a scale of $1: 5000000$ (White, 1983), that of the Horn of Africa (Friis, 1992), that of Ethiopia (Sebsebe et al., 1996, 2004; Sebsebe and Friis, 2009), and the potential vegetation map of Ethiopia at a scale of $1: 2000000$ (Friis et al., 2011). The vegetation maps compiled by Pichi Sermolli (1957), von Breitenbach (1963), White (1983), and Friis (1992) were published many years ago at small scales; therefore, they cannot provide detailed information of the actual vegetation of the Lake Tana basin. The potential vegetation map compiled by Friis et al. (2011) also cannot reflect the actual status of the vegetation of Lake Tana basin. Another map that could present the vegetation of the Lake Tana basin is the land cover/use map developed by Shimelis et al. (2008), at a scale of approximately 1:1700 000. However, only large patches of vegetation were mapped, and many patches were merged or omitted. Therefore, there is a shortage of detailed vegetation data in the Lake Tana basin, which limits the effectiveness of planning vegetation management and biodiversity conservation. Therefore, in this research, we produced a vegetation map of the Lake Tana basin using high-spatialresolution satellite images provided by Google Earth and field survey data. We believe that this map will aid vegetation and biodiversity conservation in the Lake Tana basin.

\section{Study area}

Lake Tana is located in the highlands of northwestern Ethiopia (Fig. 1). The average altitude of Lake Tana is approximately $1800 \mathrm{~m}$, and the area of the basin (including water surface area) is $15096 \mathrm{~km}^{2}$. The water surface area is $3000-3600 \mathrm{~km}^{2}$ and the maximum water depth is $14 \mathrm{~m}$. Gilgel Abay, Ribb, Gumera, and Megech are the most important rivers feeding into Lake Tana and contribute over $90 \%$ of the total inflow.

The zonal vegetation of the Lake Tana basin is dry evergreen Afromontane forest. However, only small patches of remnant forest currently exist due to heavy deforestation. The biodiversity of the Lake Tana basin is rich, and many endemic plant species grow in this catchment. There are large

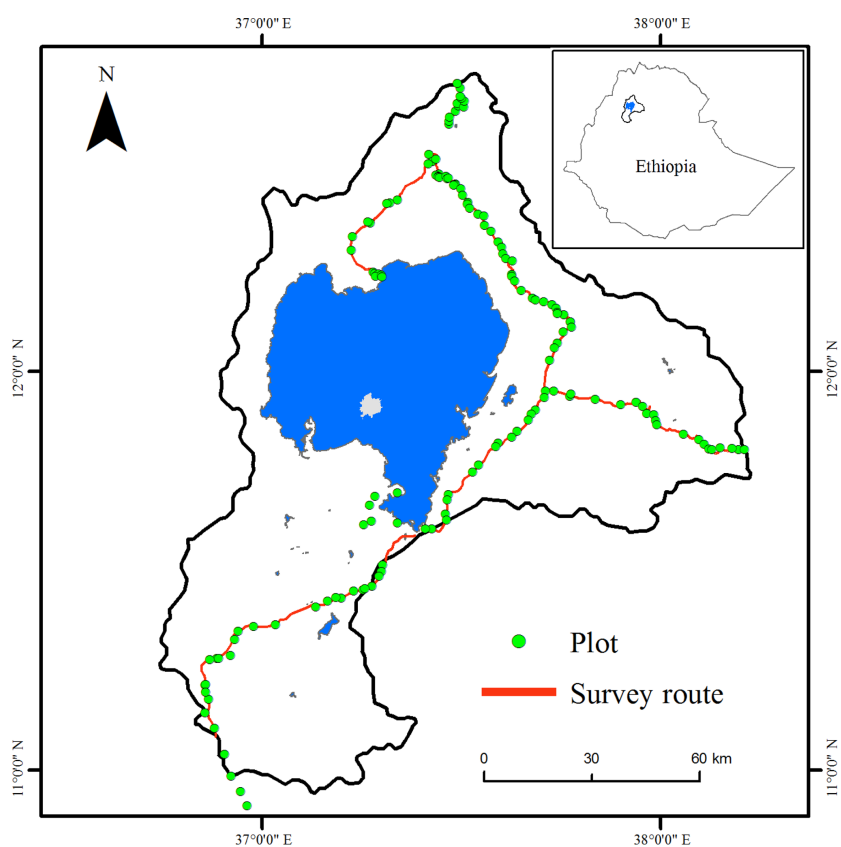

Figure 1. Location of the Lake Tana basin, survey route, and plots.

areas of wetlands in this basin, which are the home of many endemic birds.

\section{Data and method}

\subsection{Data sources}

High-spatial-resolution satellite images provided by Google Earth and vegetation survey data were used to map vegetation. Field vegetation surveys were performed in 2015 and 2016, during which 156 vegetation plots were investigated (Fig. 1).

Prior to conducting the vegetation surveys in the Lake Tana basin, we selected survey sites using Google Earth. These sites were located within the large vegetation patch with a uniform appearance. When we reached a selected site, we placed the plot in the central area of the vegetation patch, at least $30 \mathrm{~m}$ away from the boundary. We recorded the name, coverage, and height of each species in the vegetation plot $(1 \mathrm{~m} \times 1 \mathrm{~m}$ for herbaceous, $5 \mathrm{~m} \times 5 \mathrm{~m}$ for shrub, and $20 \mathrm{~m} \times 20 \mathrm{~m}$ for arboreal plants). Three Ethiopian geobotanists participated in these vegetation surveys, who were responsible for species identification. They also helped us to assess the reasonability of the sites selected for the vegetation survey.

In addition to the Google Earth images and surveyed vegetation plots, the Atlas of the Potential Vegetation of Ethiopia compiled by Friis et al. (2011) was an important reference in this research. 


\subsection{Vegetation classification system}

Shimelis et al. (2008) classified the vegetation and land cover of the Lake Tana basin into 13 types: forest-mixed, forestevergreen, forest-deciduous, range-bush, pasture, rangegrasses, wetland-mixed, plantation, barley, teff, maize, urban, and water areas. Based on this vegetation classification system and suggestions from the Ethiopian geobotanists, the vegetation of the Lake Tana basin was categorized into seven groups: natural forest, woodland, plantation forest, bushland, grassland, wetland, and cultivated land. Three types of nonvegetation cover, i.e., water body, village and urban, were also mapped. Sub-types of these vegetation groups exist for variations in dominant species; however, we did not differentiate these sub-types owing to the limitations of the spatial resolution of the satellite images.

\subsection{Interpretation marks}

Fifty-two vegetation plots were randomly selected to establish interpretation marks. The coordinates of the vegetation plots were recorded and then transformed into KML files, which could be read by the Google Earth software. These KML files were opened in Google Earth and used to establish interpretation marks according to the color and texture characteristics of the vegetation in the satellite images (Fig. 2). The keys to image interpretation are as follows:

- Natural forest. Crowns are dense, usually tightly packed, and overlapping in clusters. The texture is coarse and the color is green or dark green. This type is mostly located around churches or near rivers.

- Woodland. This vegetation cover appeared as large crowned trees. The color is green or yellow-green and the texture is coarse. The canopy may be tightly packed or open with visible patches of understory.

- Plantation forest. Uniformly spaced dense trees are almost the same height. The color is dark green and the texture is coarse. The crowns are tightly packed with an almost uniform texture. The patch tends to be rectangular with straight rows.

- Bushland. The signature feature of this type is a coarse texture with mottled tones. Shrubs are unevenly spaced, and tend to clump, presenting a mottled pattern in the area. There may be a mixture of scattered trees in the bushland.

- Grassland. This type is almost smooth in appearance. The color is light green, beige, or light brown. Cow trails may be visible.

- Wetland. Coarse texture, dense, and dark green with irregular edges near pools, ponds, rivers, or lakes. Scattered shrubs and trees may exist.

\subsection{Method of vectorization}

Visual interpretation was employed to identify vegetation in Google Earth based on the established interpretation marks. The "Add polygon" tool was used to vectorize the vegetation patches at a scale of approximately $1: 5000$. Three people participated in the vectorization of vegetation patches. To ensure that the identification criteria were consistent, vegetation/land identification was only conducted by one person.

The vegetation identification process received beneficial guidance from Ethiopian researchers who are familiar with the vegetation of the Lake Tana basin. We worked with Ethiopian geobotanists in two ways. The first is face-to-face co-working. From 27 October to 7 December 2015, during the vegetation survey period in the Lake Tana basin, we worked with Ethiopian geobotanists to identify vegetation. From 10 to 25 October 2016, we invited Ethiopian geobotanists to China to make revisions to our vegetation map. From 16 December 2016 to 2 January 2017, we collected vegetation plots in the Lake Tana basin to validate and revise the vegetation map with Ethiopian geobotanists. Secondly, we also consulted with Ethiopian geobotanists via email when we were uncertain about the results of vegetation identification.

Our collaborators from Ethiopia are geobotanists who are very familiar with the Lake Tana basin. They greatly contributed to the identification of vegetation, and their professional knowledge guaranteed the quality of this vegetation map.

The vectorization and identification process continued for over one and a half years, and 33171 polygons were generated to represent the vegetation patches of the Lake Tana basin on the map. The other 104 surveyed plots were used to assess the accuracy of vegetation identification. The result of this assessment is presented in Table 1.

The KML files of all vegetation types were imported into the Global Mapper software (v16.0) and then transformed into SHP files, which could be read by ArcGIS (v9.3, ESRI). In ArcGIS, the vegetation type of each polygon was marked in an attributes table and all SHP files were merged into one. Finally, a vegetation map was designed and exported for printing on A1-sized paper (approximate scale of 1 : $310000)$ (Fig. 3).

\subsection{Projected and geographic coordinate systems}

Projected Coordinate System: WGS_1984_UTM_ Zone_37N; Projection: Transverse_Mercator; False_Easting: 500000.0000000; False_Northing: 0.00000000; Central_Meridian: 39.00000000; Scale_Factor: 0.99960000 ; Latitude_Of_Origin: 0.00000000; Linear Unit: Meter.

Geographic Coordinate System: GCS_WGS_1984; Datum: D_WGS_1984; Prime Meridian: Greenwich; Angular Unit: Degree. 


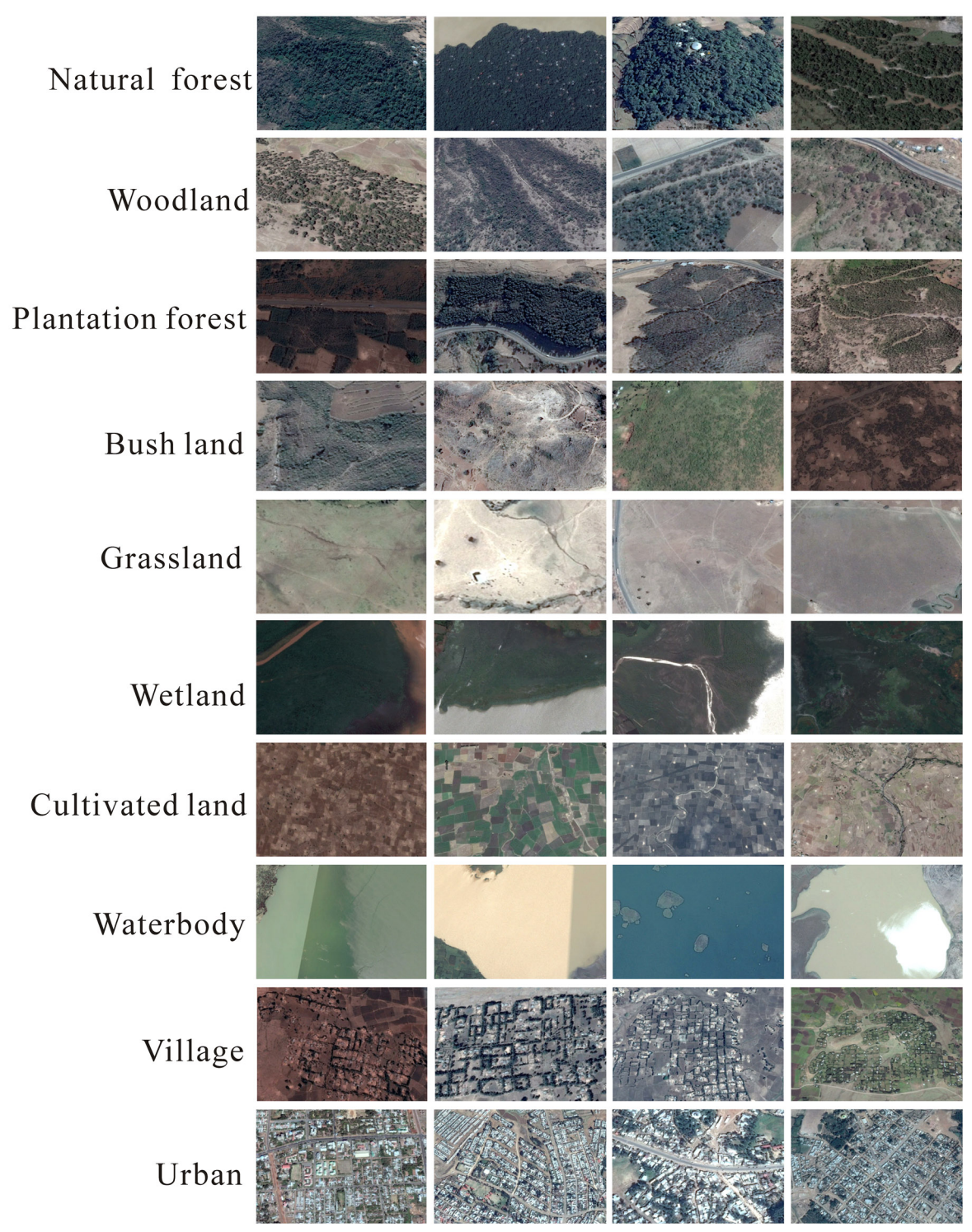

Figure 2. Interpretation marks based on the Google Earth images.

\section{Results}

\subsection{Accuracy of vegetation identification}

Table 1 presents the accuracy matrix of vegetation identification, which was calculated based on the surveyed plots. Plantation forests were all correctly identified. The identification accuracy of grassland was also very high, with only a few plots identified as cultivated land. The identification accuracy of bushland, forest, and wetland is lower than that of grassland and plantation forest but higher than that of woodland.

Other land cover types, such as water bodies, villages, and urban areas, are easily identified; therefore, we did not perform accuracy assessment for these three land cover types.

\subsection{Description of vegetation/land cover types}

\subsubsection{Natural forest}

Two types of natural forest exist in this basin: dry evergreen Afromontane and riverine forest (Friis et al., 2011). The altitude at which dry evergreen Afromontane forests occur ranges from 1500 to $2700 \mathrm{~m}$. The mean annual temperature and rainfall are $14-25^{\circ} \mathrm{C}$ and $700-1100 \mathrm{~mm}$ (Friis, 1992). The high amplitude of altitude and rainfall result in complex habitats and species compositions. The characteristic arborous layer species are Podocarpus falcatus and Juniperus procera, and the dominant understory species are Croton macrostachyus, Ficus spp., Olea europaea subsp. cuspidata, Trema orientalis, and Maesa lanceolata. 
Table 1. Accuracy of vegetation identification (\%).

\begin{tabular}{lrrrrrrr}
\hline & Bushland & Cultivated land & Natural forest & Grassland & Plantation forest & Wetland & Woodland \\
\hline Bushland & 85 & 0 & 6.3 & 0 & 0 & 0 & 12.5 \\
Cultivated land & 0 & 100 & 0 & 3.4 & 0 & 0 & 0 \\
Natural forest & 0 & 0 & 87.4 & 0 & 0 & 0 & 12.5 \\
Grassland & 0 & 0 & 0 & 96.6 & 0 & 15.4 & 0 \\
Plantation forest & 0 & 0 & 0 & 0 & 100 & 0 & 0 \\
Wetland & 0 & 0 & 0 & 0 & 0 & 84.6 & 0 \\
Woodland & 15 & 0 & 6.3 & 0 & 0 & 0 & 75 \\
\hline
\end{tabular}

Numbers in the table represent the percent of one vegetation type classified into another category. Taking bushland for instance, " 85 " means that $85 \%$ of bushland plots were correctly identified as bushland and " 15 " means that $15 \%$ of bushland plots were identified as woodland.

Riverine forest is predominantly located near lakes and rivers, and the dominant species are Diospyros mespiliformis, Mimusops kummel, and Syzygium guineense.

Owing to the continuous expansion of cropland in the past, the natural forest was gradually destroyed. Small patches of remnant forests can be found in two main forms in this region: protected state and church forests.

\subsubsection{Woodland}

There are two types of woodland in the Lake Tana basin: Combretum-Terminalia and Acacia-Commiphora woodland (IBC, 2005; Friis et al., 2011).

Combretum-Terminalia woodlands occupy areas with an altitude of 500-1900 m. They are usually located in humid lowland areas or in river valleys. The characteristic species of Combretum-Terminalia woodland are Combretum spp., Terminalia spp., Oxytenanthera abyssinica, Boswellia papyrifera, Anogeissus leiocarpa, Stereospermum kunthianum, Pterocarpus lucens, Lonchocarpus laxiflorus, Lannea spp., Albizia malacophylla, and Entada africana. Most of these species are small trees with large deciduous leaves, and they often grow together with Oxytenanthera abyssinica. The understory is a mixture of herbs and grasses. Dominant herbaceous species include Justicia spp., Barleria spp., Eulophia spp., Chlorophytum spp., Hossolunda opposita, and Ledeburia spp.

Acacia-Commiphora woodlands usually occupy dry slopes with an altitude of 1000-1900 m (ANRS, 2004). Such habitats are characterized by large variations in soil and topography and diverse biotic and ecological elements. Most of the plant species in Acacia-Commiphora woodland have small deciduous or leathery evergreen leaves.

There is a large variation in the stand density of AcaciaCommiphora woodlands, and such woodlands were observed with three different formations: dense forest with closed canopies, scattered individuals, and wooded grassland. Acacia-Commiphora woodlands are also known for containing some Acacia, Boswellia, and Commiphora species, which can be used to produce gum and resin.

\subsubsection{Plantation forest}

Eucalyptus species are the main species of plantation forests. Cupressus lusitanica and pine species were also planted in some areas. In addition, Acacia mearnsii was also found in the southern area of the Lake Tana basin.

There are approximately 600 Eucalyptus species worldwide, and over 120 of these are found in Ethiopia (Alemayehu, 2017). Eucalyptus globulus and Eucalyptus camaldulensis are the most common and widely planted species in Ethiopia. E. globulus is usually planted in areas above $2200 \mathrm{~m}$ in altitude, and E. camaldulensis is planted in regions with an altitude of 1700-2400 m.

The development of Eucalyptus plantations was widely criticized as they suppress the growth of indigenous species and use large amounts of underground water. However, the plantation area of Eucalyptus forest has increased rapidly in the past 15 years (Birru et al., 2003).

\subsubsection{Bushland}

Bushland often occurs in areas with shallow soil and steep slopes, such as hills, escarpments, mountains, and gorge slopes. There is usually grassland on the bottom of bushland, which forms a bush-grass complex. The dominant woody species of bushland are Maytenus senegalensis, Carissa spinarum, Clausena anisata, Clerodendrum myricoides, Grewia ferruginea, Caesalpinia decapetala, Ficus verruculosa, Calpurnia aurea, Erica arborea, Hypericum revolutum, Vernonia spp., Senna spp., Cordia spp., Acacia spp., Commiphora Africana, and Indigofera spp.

\subsubsection{Grassland}

Grasslands are mainly distributed along rivers, around villages, on mountains and hilltops, on slopes, and on highlands with stony and shallow soils. Common grassland species are Eragrostis spp., Pennisetum spp., Panicum spp., Echinochloa spp., Setaria spp., Hyparrhenia spp., Cymbopogon spp., and Sorghum spp. Scattered shrubs are present on grassland, such as Senna spp. and Maytenus senegalensis. 


\subsubsection{Wetland}

Wetlands are distributed around Lake Tana and along its tributaries. Hygrophila auriculata, Cyprus papyrus, Typha latifolia, Phragmites australis, Nymphaea caerulea, Juncus dregeanus, Floscopa glomerata, Eriocaulon spp., and Xyris capensis are the main species of wetlands.

Wetlands have rich biodiversity and provide diverse ecological functions. The lake and its tributaries are the home of 28 fish species, 15 of which are endemic to Ethiopia. Over 300 species of birds have been observed and recorded in the Lake Tana basin, which has been defined as an international bird site by BirdLife International (BLI) (Shimelis, 2013).

\subsubsection{Cultivated land}

Teff, sorghum, chickpea, rice, maize, and sesame are widely planted in the Lake Tana basin. These crops are often mixed with endemic or exotic arbor species, such as Croton macrostachyus, several Acacia species, Albizia gummifera, Cordia africana, Juniperus procera, Grevillea robusta, and Sesbania sesban, which forms a complex agroforestry system.

Many fruits are planted in agroforestry, such as Mangifera indica, Persea americana, Carica papaya, Citrus sinensis, Citrus aurantifolia, Rhamnus prinoides, Mimusops kummel, and Syzygium guineense.

\subsubsection{Water body}

Lake Tana is the largest water body in this watershed. The total area of Lake Tana is $3080.8 \mathrm{~km}^{2}$, which constitutes $98.98 \%$ of the total water surface area.

\subsubsection{Village}

Many of the villages in the Lake Tana basin are very small. These small villages are sparsely distributed throughout the landscape. It is difficult to vectorize all village patches; therefore, only large villages were identified and vectorized in this research.

\subsubsection{Urban}

There are two large cities in the Lake Tana basin: Gonder and Bahir Dar. The total urban area is $69.04 \mathrm{~km}^{2}$, occupying $0.46 \%$ of the Lake Tana basin.

\section{Discussions}

\subsection{Vegetation/land classification system}

IGBP DISCover (Belward, 1996) and the Land Cover Classification System (Di Gregorio and Jansen, 2000) are more detailed than the system adopted in this research. However, these two systems require more information to classify different land cover types. For example, canopy cover and plant height are required to differentiate closed from open shrublands. The differentiation of woody savannas, savannas, and grasslands also depends on the canopy cover and plant height of upper-layer vegetation. In addition, satellite images generated during different seasons were required to differentiate "evergreen forest" from "deciduous forest". However, it is difficult to collect such information, and it is not easy to identify these vegetation covers based only on Google Earth images.

After over 50 years of deforestation and land reclamation, most needle leaf forests in the Lake Tana basin have been destroyed for the timber trade. Many researchers deemed that there is no typical "savanna" in the Lake Tana basin based on the IGBP system, and they prefer to use "grassland" in the land/vegetation classification (Shimelis et al., 2008; Aster and Seleshi, 2009; Wubneh and Amare, 2017).

Therefore, in this research, we merged different forest types (evergreen needle leaf, evergreen broadleaf, deciduous needle leaf, deciduous broadleaf, and mixed forest) into natural forest. We also merged closed and open shrublands into bushland, and woody savannas, savannas, and grasslands were merged into grasslands.

Woodland was separated from the natural forest category. Owing to the altitude at which woodland exists, the species composition and community physiognomy are quite different from that of natural forest (dry evergreen Afromontane and riverine forests) (Friis et al., 2011).

Plantation forest (Eucalyptus) is a very important forest type in the Lake Tana basin as it plays a vital role in the development of forestry and agriculture. The Ethiopian ecologists strongly suggested that we differentiate Eucalyptus from other forest types.

Finally, the vegetation of the Lake Tana basin was categorized into seven groups: natural forest, woodland, plantation forest, bushland, grassland, wetland, and cultivated land. Three types of non-vegetation cover, i.e., water body, village, and urban, were also mapped in this research.

\subsection{Accuracy of vegetation identification}

The validation using the surveyed plots indicated that the identification accuracy exceeded $85 \%$ for most vegetation/land cover types, except woodland. Table 1 shows that misclassifications occurred more between bushland, woodland, and natural forest. Bushlands are usually composed of low and sparse shrubs. However, in some areas, shrubs can grow to be tall and dense. It is difficult to differentiate bushlands from woodlands and natural forests if this is the case. Woodlands mainly consist of arboreal species and are usually regarded as sparse "forest". However, it is not easy to distinguish between natural forest and dense woodland using remote sensing images. 


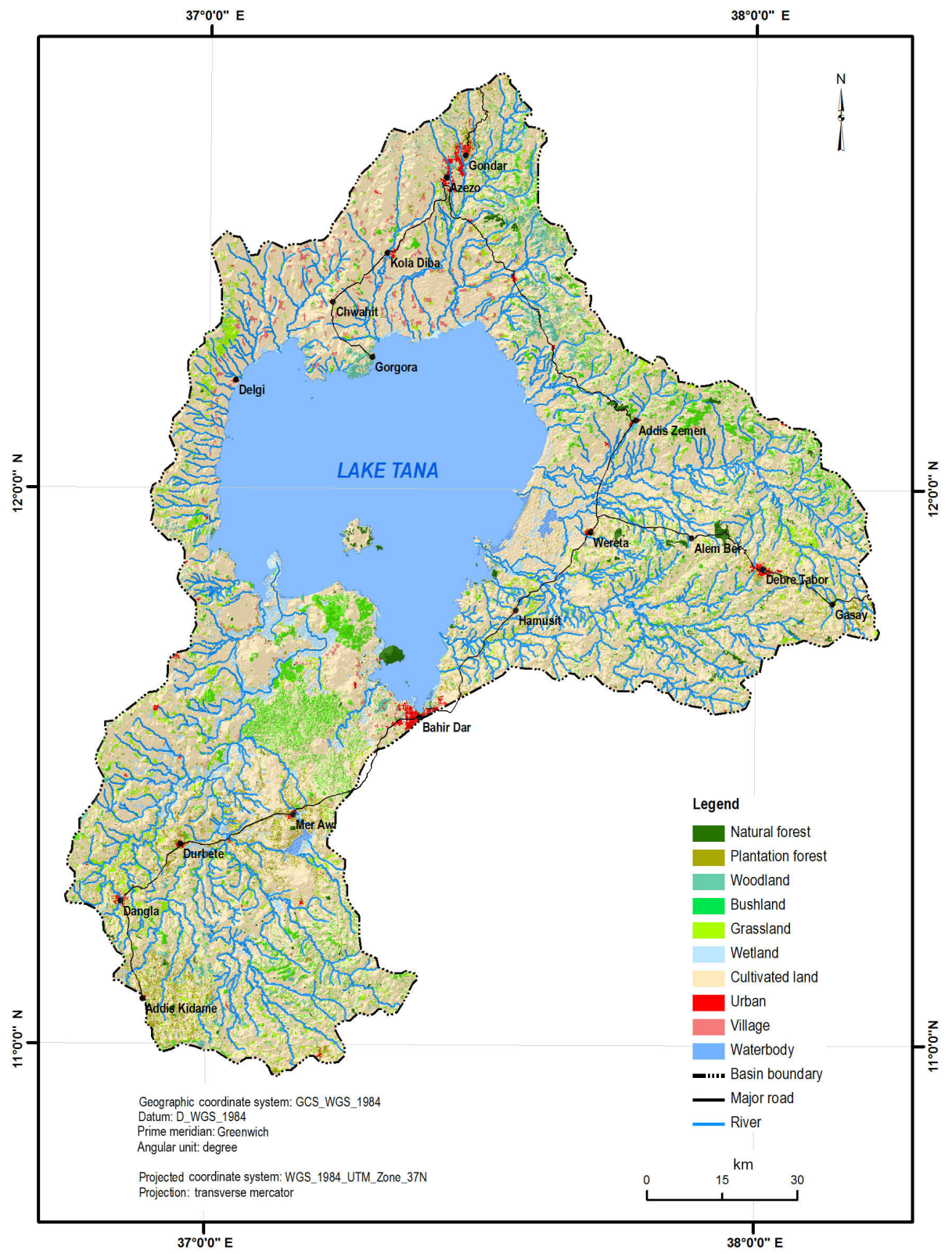

Figure 3. Vegetation map of the Lake Tana basin, Ethiopia.

Misclassification also occurred between grassland, wetland, and cultivated land. The color and texture of grassland and wetland (especially seasonal wetlands) are similar during the dry season. Therefore, wetlands can easily be identified as grasslands. The color and texture of abandoned cultivated land are very similar to those of grassland. Therefore, grasslands were identified as cultivated lands.

The number and distribution of sampling sites significantly influence the validation of remote sensing data products (Darvishzadeh et al., 2011). In this research, the vegetation plots used to validate the result of vegetation identifica- tion were collected along a cement road, which caused biases and uncertainties in the validation.

\subsection{Flaws existed in vectorization}

The polygons of vegetation patches were generated through manual delineation. The quality of the vector data was greatly influenced by the technicians who conducted the vectorization. Although a training course was held to unify the vectorization criteria, some flaws still occurred during vectorization. We found that the boundaries of some polygons 
were not delineated strictly along the border of vegetation patches, which negatively affected the quality of this dataset.

Another issue is that there were gaps between polygons caused by the vectorization approach adopted in this research. The polygons of vegetation patches were delineated by the "Add polygon" tool of Google Earth. If two patches with different vegetation covers are connected or they are very close, then a gap will be created between the two vegetation polygons.

We did not interpret patches of cultivated land because it is difficult to determine which crops are planted among them using Google Earth images. Another reason is that our main objective in this research was to map the natural vegetation of the Lake Tana basin.

\subsection{Potential uses of this dataset}

This vegetation map provides detailed data on the spatial distribution of vegetation in Lake Tana basin. It could be used to aid local governments in producing development plans for forestry, agriculture, and stockbreeding in the Lake Tana basin. This vegetation map could also be used in the conservation of natural resources as it can help managers to determine the conservation targets for the Lake Tana basin. Moreover, this vegetation map could be used as basic data for studying changes in land use, restoration ecology, landscape ecology, ecological modeling, and hydrological modeling.

\section{Data availability}

The dataset developed in this research includes five subdatasets: basin boundary, city, major road, river, and vegetation cover (Song et al., 2018). The DOI for the dataset is https://doi.org/10.4121/uuid:48d45053-36f6-411b96b1-7ae0e22d56d0.

Author contributions. WD and SC designed the research, SC, LN, YB, AA, ZL, and WD collected the data, and SC wrote the manuscript. WD and $\mathrm{LN}$ revised the manuscript.

Competing interests. The authors declare that they have no conflict of interest.

Acknowledgements. This study was funded by the National Key Research and Development Program of China (2017YFC0503801, 2016YFC0500103), the CASEarth project (XDA91050402) of Chinese Academy of Sciences, the Ministry of Sciences and Technology (International Science \& Technology Cooperation Program of China - 2014DFG32090), and the State Key Laboratory of Vegetation and Environmental Change, Institute of Botany, Chinese Academy of Sciences.
Edited by: David Carlson

Reviewed by: two anonymous referees

\section{References}

Alelign, A., Teketay, D., Yemshaw, Y., and Edwards, S.: Diversity and status of regeneration of woody plants on the Peninsula of Zegie, Northwestern Ethiopia, Trop. Ecol., 48, 37-49, 2007.

Alemayehu, W.: Forest Resources in Amhara: Brief Description, Distribution and Status, in: Social and Ecological System Dynamics-Characteristics, Trends, and Integration in the Lake Tana Basin, edited by: Krystyna, S., Goraw, G., and Shimelis, A., Ethiopia, Springer, 231-243, 2017.

Amhara National Regional State (ANRS): A strategic plan for the sustainable development, conservation, and management of the woody biomass resources, Final Report, 2004.

Aster, D. Y. and Seleshi, B. A.: Characterization and atlas of the Blue Nile Basin and its subbasins, International Water Management Institute, available at: http://publications.iwmi.org/pdf/ H042502.pdf (last access: 12 November 2018), 2009.

Ayalew, W.: Improving management of shoreline and riparian wetland ecosystems: the case of Lake Tana catchment, Ecohydrology Hydrobiology, 10, 123-132, https://doi.org/10.2478/v10104-011-0017-4, 2010.

Belward, A. S. (Ed.): The IGBP-DIS Global $1 \mathrm{~km}$ Land Cover Data Set (DISCover): proposal and implementation plans, IGBPDIS Working Paper 13, International Geosphere-Biosphere Programme Data and Information Services, Toulouse, France, 1996.

Bijan, D. and Shimelis, G. S.: Combined 3D hydrodynamic and watershed modelling of Lake Tana, Ethiopia, J. Hydrol., 398, 44-64, https://doi.org/10.1016/j.jhydrol.2010.12.009, 2011.

Birru, Y., Anteneh, A., and Tadele, A.: Expansion of eucalyptus woodlots in the fertile soils of the highlands of Ethiopia: could it be a treat on future cropland use?, J. Agr. Sci., 5, 97-107, https://doi.org/10.5539/jas.v5n8p97, 2003.

Bishaw, B.: Deforestation and land degradation in the Ethiopian highlands: a strategy for physical recovery, Northeast African Studies, 8, 7-26, https://doi.org/10.1353/nas.2005.0014, 2001.

Darvishzadeh, R., Atzberger, C., Skidmore, A., and Schlerf, M.: Mapping grassland leaf area index with airborne hyperspectral imagery: A comparison study of statistical approaches and inversion of radiative transfer models, ISPRS J. Photogramm., 66, 894-906, 2011.

Di Gregorio, A. and Jansen, L.: Land cover classification system, concepts and user manual, GCP/RAF/287/ITA Africover, Food and Agriculture Organization of the United Nations Publishing Service, Rome, 2000.

Friis, I.: Forest and forest trees of northeast tropical Africa-their nature habitats and distribution patterns in Ethiopia, Djibouti and Somalia, Kew Bull. Additional Series, No. 15, i-iv, 1-396, London, HMSO, 1992.

Friis, I., Sebsebe, D., and van Paulo, B.: Atlas of the Potential Vegetation of Ethiopia, Addis Ababa, Addis Ababa University Press \& Shama Books, 2011.

Institute of biodiversity conservation (IBC): Ethiopian Biodiversity Strategy and Action Plan, available at: http://www.cbd.int/doc/ world/et/et-nbsap-01-en.pdf (last access: 12 November 2018), 2005. 
International Fund for Agriculture Development (IFAD): Community-based Integrated Natural Resources Management in the Lake Tana Watershed, Ethiopia, on Forestry, Agroforestry, Soil Conservation, Bahir Dar, 2007a.

International Fund for Agriculture Development (IFAD): Community-based integrated natural resources management project in Lake Tana Watershed, Ethiopia (3rd draft), Bahir Dar, 2007b.

Pichi Sermolli, R.: Una carta geobotanica dell's Africa Orientale (Eritrea, Ethiopia, Somalia), Webbia, 13, 15-132, 1 map, 1957.

Sebsebe, D. and Friis, I.: The vegetation type in Ethiopia, in: The Flora of Ethiopia and Eritrea, edited by: Hedberg, I., Friis, I., and Persson, E., National Herbarium, Addis Abeba \& Uppsala University, Uppsala, 8, 27-32, 2009.

Sebsebe, D., Mengistu, W., and Yilma, D.: Ethiopia's natural resource base, in: Important Bird Areas of Ethiopia. A First Inventory, edited by: Edwards, S., Ethiopian Wildlife and Natural History Society, Addis Abeba, 36-53, 1996.

Sebsebe, D., Cribb, P., and Rasmussen, F.: Field guide to Ethiopia orchids, Royal Botanic Gardens, Kew Bulletin, 59, 653, 2004.

Shimelis, A. Z.: Birds of Lake Tana area, Ethiopia, A photographic field guide, View Graphics and Printers, Addis Ababa, 2013.

Shimelis, G. S., Ragahavan, S., and Bijan, D.: Hydrological modelling in the Lake Tana Basin, Ethiopia using SWAT model, The Open Hydrology Journal, 2, 49-62, https://doi.org/10.2174/1874378100802010049, 2008.
Song, C. Y., Nigatu, L., Beneye, Y., Abdulahi, A., Zhang, L., and $\mathrm{Wu}, \mathrm{D}$. X.: Vegetation map of Lake Tana basin, IBCAS, Dataset, https://doi.org/10.4121/uuid:48d45053-36f6411b-96b1-7ae0e22d56d0, 2018.

Teketay, D.: Deforestation, wood famine and environmental degradation in Ethiopia's highland ecosystems: urgent need for action, Northeast African Studies, 8, 53-76, https://doi.org/10.1353/nas.1995.0010, 2001.

von Breitenbach, F.: The Indigenous Trees of Ethiopia, 2nd revised and enlarged edition, Ethiopia Forestry Association, Addis Abeda, 1963.

White, F.: The vegetation of Africa. A descriptive memoir to accompany the UNESCO/AETFAT/UNSO vegetation map of Africa with map in 3 parts + legend, Paris, UNESCO, 356 pp., 1983.

Wubneh, B. A. and Amare S. M.: Land Use and Watershed Management Practices in Lake Tana Basin, in: Social and Ecological System Dynamics-Characteristics, Trends, and Integration in the Lake Tana Basin, edited by: Krystyna, S., Goraw, G., and Shimelis, A., Ethiopia, Springer, 231-243, 2017.

Yimenu, A.: Characterization of domestic wastewater disposal as point source pollution in southern gulf of Lake Tana, Northwestern Ethiopia. MSc. Thesis, Environmental Science Program, School of Graduate Studies, Addis Ababa University, Addis Ababa, Ethiopia, 2005. 